\title{
The effects of periparturient administration of flunixin meglumine on the health and production of dairy cattle
}

\author{
N. C. Newby, ${ }^{*}$ K. E. Leslie, ${ }^{*}$ H. D. Putnam Dingwell, ${ }^{*}$ D. F. Kelton, ${ }^{*}$ D. M. Weary,† L. Neuder,‡ S. T. Millman,§ \\ and T. F. Duffield*1 \\ *Department of Population Medicine, Ontario Veterinary College, University of Guelph, Guelph, ON, Canada N1G 2W1 \\ †Animal Welfare Program, University of British Columbia, Vancouver, BC, Canada V6T 1 Z4 \\ łLarge Animal Clinical Sciences, College of Veterinary Medicine, Michigan State University, East Lansing 48824 \\ §Veterinary Diagnostic and Production Animal Medicine, lowa State University, Ames 50011
}

\begin{abstract}
Research on the assessment and management of pain in cows following difficult or assisted calving is still limited, especially on the effects of analgesics intended to mitigate this pain. The purpose of this study was to assess the effects of flunixin meglumine on the health and production of Holstein cows after calving. In total, 34 flunixin-treated and 38 placebo-treated animals were enrolled in a precalving treatment trial. A total of 633 animals given flunixin and 632 animals administered a placebo were enrolled in a postcalving treatment trial. In both cases, animals were randomly assigned to treatment, and researchers were blind to treatment condition until after analysis. A total of 1,265 animal records were analyzed for milk production for the first $14 \mathrm{~d}$ in milk and health outcomes for the first $30 \mathrm{~d}$ in milk. Animals treated with flunixin meglumine before calving had a significantly increased risk of stillbirth. Animals treated immediately after calving had increased odds of having a retained placenta and, in turn, increased risk of a high temperature, decreased milk production, and an increased risk of developing metritis. The administration of flunixin meglumine within $24 \mathrm{~h}$ of parturition is not recommended in dairy cattle.
\end{abstract}

Key words: dystocia, nonsteroidal anti-inflammatory drug (NSAID), retained placenta, metritis

\section{INTRODUCTION}

Calving can cause stress and pain for the cow. Calving is more likely to be painful when calving is assisted, and Holstein calvings commonly require some assistance, particularly for primiparous animals (Mee, 2008). Bruising and lacerations of the vagina and uterus

Received July 15, 2016.

Accepted September 30, 2016.

${ }^{1}$ Corresponding author: tduffiel@uoguelph.ca because of dystocia likely cause pain for several days after calving. The concentration of the inflammatory protein haptoglobin is elevated for a 2-wk period after parturition (Bionaz et al., 2007), indicating tissue damage and suggesting that inflammatory pain may affect cattle for this period.

Little research to date has addressed pain management after calving. Newby et al. (2013) administered meloxicam $24 \mathrm{~h}$ after assisted calving and found that treated animals visited the feed bunk more often and spent more time at the feed bunk compared with their placebo counterparts. Pain may also have secondary effects; for example, reducing milk production after calving and increasing the risk of some diseases. Newby et al. (2013) assessed the effect of meloxicam on DMI, milk production, blood parameters, and health events after calving but found no effects. Richards et al. (2009) administered ketoprofen immediately after calving and again $24 \mathrm{~h}$ later, and found that ketoprofen-treated cows were less likely to incur a retained placenta compared with untreated cows.

To our knowledge, no study has yet assessed the effects of the nonsteroidal anti-inflammatory drug (NSAID) flunixin meglumine on the health and production of cows after calving. Our hypothesis was that flunixin meglumine would mitigate the pain, resulting in a faster recovery, as evidenced by improved milk production and reduced disease in treated animals.

\section{MATERIALS AND METHODS}

This study was conducted at a large commercial dairy farm (study site 1) and at a dairy research facility (study site 2). The trial period was from June 2006 to June 2007.

\section{Study Site 1: Large Commercial Dairy Farm}

Approximately 1,260 Holstein transition primiparous and multiparous animals were enrolled $3 \mathrm{wk}$ before their 
expected calving date. Complete data were available for 1,174 cows. Study animals were housed and managed at Green Meadow Farms (GMF; Elsie, MI). The cattle were housed in a freestall facility during all phases of this trial except during the parturition process, when they were housed in box stalls. After calving, cows were milked twice daily in a milking parlor. Feeding procedures were conducted according to GMF standard management procedures, using a prefresh TMR ration and a milking herd TMR. All rations were balanced by the herd nutritionist to meet or exceed National Research Council requirements for Holstein dairy cows according to stage of lactation and production. Data on production, health events, reproductive performance, and removal from the herd were recorded using DairyComp 305 (Valley Ag Software, Tulare, CA).

The enrollment period was from June to November 2006. Any prepartum Holstein primiparous or multiparous animals at Green Meadow Farms that was clinically normal at the time of enrollment and at calving were eligible for inclusion in this study. Any primiparous or multiparous animals that were currently being treated for systemic illness or had an ongoing clinical disease were not enrolled. Enrolled subjects were randomly assigned via a random number generator and blocked by parity to receive either 2 doses of flunixin meglumine $(50 \mathrm{mg} / \mathrm{mL}$, Banamine, Merck Animal Health, Madison, NJ) or placebo (sterile saline). The volume of either flunixin meglumine or saline placebo solution was $25 \mathrm{~mL}$ for multiparous cows and $22 \mathrm{~mL}$ for primiparous animals, administered via intravenous injection into the jugular vein. The calculated doses of flunixin meglumine were based upon average cow and primiparous animal weights for GMF and, in this manner, all treated animals received a USDA-approved label dose of flunixin meglumine (1.1 to $2.2 \mathrm{mg} / \mathrm{kg}$ of BW).

\section{Change of Study Protocol}

For the first 72 animals (flunixin meglumine $\mathrm{n}=34$, placebo $\mathrm{n}=38$, from June 1 to June 11, 2006), the first treatment occurred when the animal was moved to the calving box stall immediately precalving and again 18 to $36 \mathrm{~h}$ later during the morning lockup. Trial personnel were notified by the herd veterinarian after about 1 wk on the trial that there was an increase in the herd rate of stillbirths. Following unblinding of the enrolled animals, it was discovered that the stillbirth rate was greater in the flunixin-treated group compared with the placebo group ( $26.5 \%$ vs. $5.3 \%$; Fisher's exact test, $P$ $=0.02)$. Consequently, the treatment protocol was adjusted so that treatment occurred following parturition (when the animal was restrained for milking and the calf was removed from the calving pen). The administration of the treatments occurred at approximately 1 $\mathrm{h}$ postcalving and again during the next day's milking lockup at approximately $24 \mathrm{~h}$ postpartum.

The close-up dry pen was monitored every $2 \mathrm{~h}, 24$ $\mathrm{h} / \mathrm{d}$. When evidence of impending parturition in the study subjects was visible (i.e., amnion, feet, elevated tail head with straining), the animal was moved to a maternity box stall. Management of the calving event was according to documented GMF standard operating procedure. Calving difficulty was scored from 1 to 4 ( $1=$ unassisted, $2=$ easy pull with one person and no mechanical assistance, $3=$ difficult pull with 2 or more people and (or) mechanical assistance, $4=$ caesarian/ fetotomy). For assisted calvings, repositioning of the calf was recorded as a dichotomized variable. Daily milk production, daily rectal temperature (taken in the morning at first milking), and periparturient disease [i.e., left displaced abomasum, mastitis, metritis, retained placenta $(\mathbf{R P})$, ketosis] were recorded for the first $30 \mathrm{~d}$ after calving. Standard case definitions for each periparturient disease, including high temperature, were developed and used in accordance with the standard operating procedures at GMF (Table 1).

\section{Study Site 2: University of Guelph Research Dairy}

The study animals ( $\mathrm{n}=148$ Holstein transition primiparous and multiparous animals) were housed and managed at the Elora Dairy Research Station (EDRC) of the University of Guelph (Elora, ON, Canada). The animals were housed in the individual maternity pen around calving and then in a tiestall housing facility 2 d after calving. They were eligible to be enrolled only if they were clinically normal at the time of enrollment and at calving. In addition, these animals were managed using a milking parlor system and milked 2 times per day. Feeding procedures were conducted according to EDRC standard management procedures, using a prefresh TMR ration and a milking herd TMR. All rations were balanced by the herd nutritionist to meet or exceed National Research Council requirements for Holstein dairy cows according to stage of lactation and production.

Animals were randomly assigned to receive either flunixin meglumine or saline placebo at a volume of 25 $\mathrm{mL}$ for multiparous cows and $22 \mathrm{~mL}$ for primiparous animals, via intravenous injection into the jugular vein. The calculated doses of flunixin meglumine were based upon average cow and primiparous animal weights, and in this manner all treated animals received a label dose of flunixin meglumine (1.1 to $2.2 \mathrm{mg} / \mathrm{kg}$ of BW Banamine, Merck Animal Health) within $1 \mathrm{~h}$ postcalving or after finding the cow with a calf in the pen (d 0 ), 
Table 1. Standard case definition for periparturient diseases monitored in this study adapted from Kelton et al. (1998)

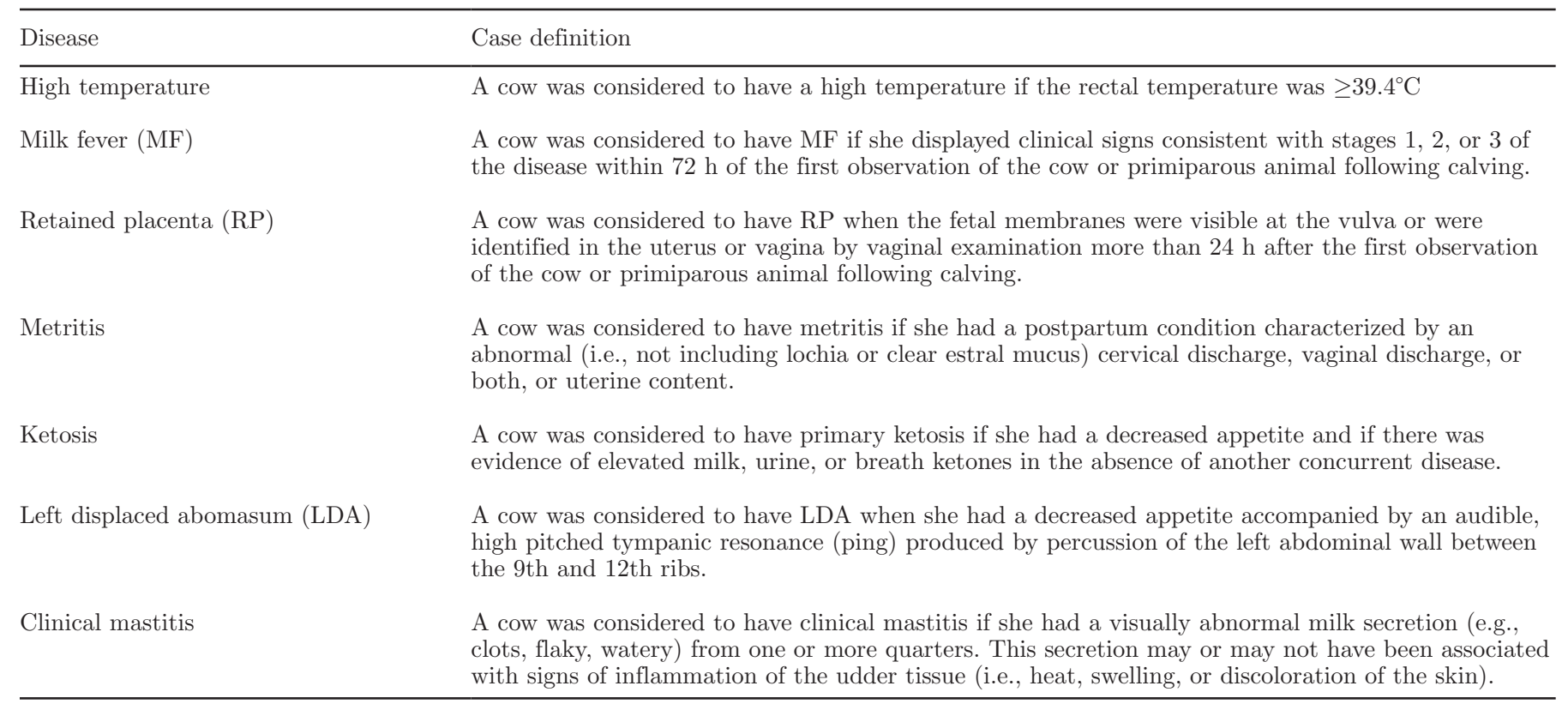

and again the following morning (d 1, approximately $24 \mathrm{~h}$ postpartum), in a formal blinded manner. The saline-treated cows in this study served as untreated non-dystocia and untreated assisted-calving control animals, and were statistically compared with flunixintreated animals for each of the outcome variables.

Dry matter intake was recorded from the time of box stall admission through $7 \mathrm{~d}$ postpartum. Daily milk production was recorded for all animals for the first 14 DIM and then weekly for the entire lactation or until the animal was removed from the herd. Periparturient disease was followed for the first 30 DIM and disease definitions used were the same as for the GMF study.

\section{Statistical Analysis}

All descriptive statistics, model building, and analyses were performed with STATA Intercooled 10.1 (StataCorp, College Station, TX). A Fisher's exact test was used to compare treatments for the first 72 animals enrolled at the GMF study site, following the observation of an abnormal number of stillbirths.

For the remainder of animals enrolled at the GMF study site under the revised protocol and for all study animals enrolled at the EDRC study site, the effect of treatment on disease events was first screened using a Chi square test and a liberal $P$-value of $<0.20$. Logistic regression models were built for each disease or event of interest that met the screening criteria (i.e., metritis, RP, and high temperature). All final models included the following variables: treatment, parity, dystocia score (dichotomized into an "unassisted" category, which included unassisted and easy pull and an "assisted" category, which included hard pull and surgery), and the fixed effect of farm. Mixed multivariable models were also built and included a random intercept for animals to account for multiple measurements being taken from each cow for the outcome of milk production. The final model for milk production included days in milk (up to 14 DIM), treatment (flunixin vs. placebo as the referent), parity (primiparous animal as the referent vs. multiparous cow), dystocia score (unassisted as the referent vs. assisted), retained placenta (RP vs. no $\mathrm{RP}$ as the referent), and farm (GMF vs. EDRC as the referent). This model was constructed using production data for the GMF facility for cows enrolled after June 11, 2006, and all EDRC cows so that all enrolled cows at each trial site were administered treatments at approximately the same time postpartum.

The standardized residuals to identify outliers at the observation level for the linear and mixed linear models and BLUPs for any outliers at the cow level for the mixed linear models were examined. No problems with model fit were observed, and no transformations were required for any of the data sets.

\section{RESULTS}

The milk production records from 1,265 animals at both study sites were analyzed, and the predicted means for the daily milk weights up to 14 DIM are shown in Figure 1. Daily milk weight increased over time, and animals from the GMF facility produced 1.1 $\mathrm{kg} / \mathrm{d}$ more milk compared with animals from EDRC 


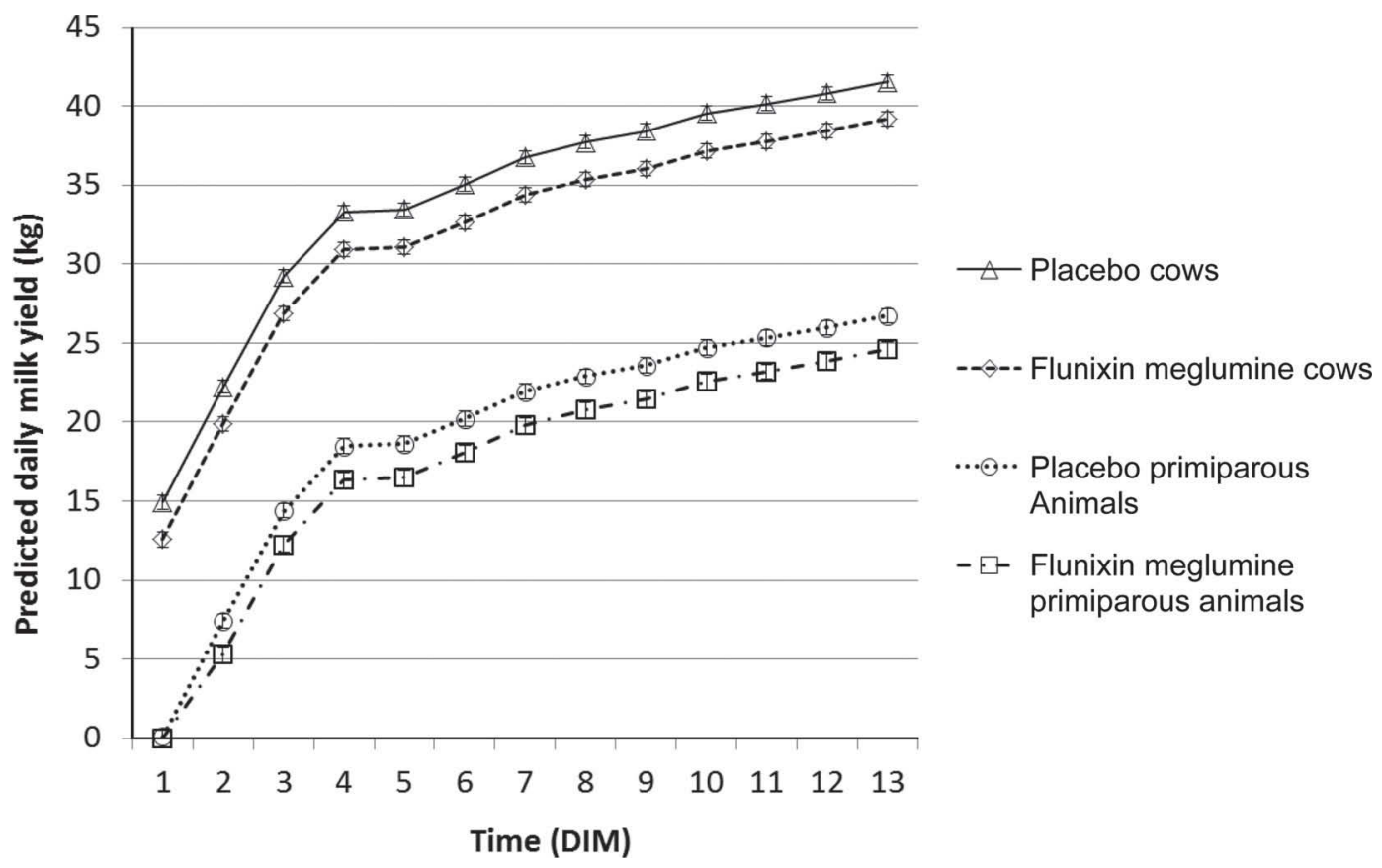

Figure 1. Predicted daily milk yield $(\mathrm{kg}$; means $\pm \mathrm{SE}$ ) based on the mixed linear regression model for the combined milk weights from primiparous animals (total $\mathrm{n}=407$; placebo $\mathrm{n}=200$; flunixin meglumine $\mathrm{n}=207$ ) and cows (total $\mathrm{n}=858$; placebo $\mathrm{n}=432$; flunixin meglumine $\mathrm{n}=426$ ) from Green Meadow Farms (Elsie, MI) and Elora Dairy Research Centre (University of Guelph, Elora, ON, Canada) study sites. Note: the flunixin meglumine groups produced significantly less milk than the placebo groups $(P<0.05)$, and cows produced significantly more milk than primiparous animals $(P<0.05)$.

(95\% CI: $0.54,1.70 ; P<0.001$ ). Multiparous cows produced $14.6 \mathrm{~kg} / \mathrm{d}$ more milk compared with primiparous animals (95\% CI: 13.7, 15.4; $P<0.001)$. Assisted animals produced $2.5 \mathrm{~kg} / \mathrm{d}$ less milk compared with unassisted animals (95\% CI: $-3.3,-1.8 ; P<0.001)$. Animals with RP produced $8.5 \mathrm{~kg} / \mathrm{d}$ less milk $(95 \%$ CI: $-9.7,-7.3 ; P<0.001)$ than animals that did not have an RP. Finally, animals treated with flunixin in the hours following calving produced $1.6 \mathrm{~kg} / \mathrm{d}$ less milk compared with animals that received the placebo $(95 \%$ CI: $-2.4,-0.88 ; P<0.001)$.

Disease outcomes were analyzed for both study sites together, and results for these outcomes are presented in Table 2. Animals treated with flunixin had greater odds of having a high temperature, which was generally associated with mastitis or metritis (odds ratio $=1.7$; 95\% CI: $1.1,2.4 ; P=0.01 ; 49 \%$ of animals with a high temperature were in the mastitis or metritis groups). Of the $51 \%$ of animals with a high temperature not in the mastitis or metritis groups, $48 \%$ had a high temperature within the first $2 \mathrm{~d}$ following calving. Flunixin treatment increased both the odds of RP (odds ratio $=2.6 ; 95 \%$ CI: $1.7,3.8 ; P<0.01)$ and the odds of metritis (odds ratio $=1.2 ; 95 \%$ CI: $0.90,1.6 ; P<0.01$ ). However, the increased likelihood of an RP appeared to lead to an increased odds of metritis (given that RP in the metritis model acted as a confounder and there was a significant increase in odds of metritis when RP was removed as a variable in the metritis model; treatment odds ratio $=1.5 ; 95 \%$ CI: $1.1,1.9, P=0.003)$. Assistance at calving doubled the odds of $\mathrm{RP}(P<$ 0.001 ; Table 2). None of the other disease outcomes differed between treatment groups. Multiparous animals had greater odds for most of the disease outcomes compared with primiparous animals, except for metritis where primiparous animals were at higher risk $(P<$ 0.001; Table 2). Assisted calvings increased the odds of all disease outcomes compared with unassisted calvings $(P<0.001$; Table 2).

Dry matter intake recorded at EDRC did not differ between placebo and flunixin groups $(\beta=0.28 \mathrm{~kg} / \mathrm{d}$; 95\% CI: $-0.66,1.2 ; P=0.57)$. Multiparous animals ate more than primiparous animals $(\beta=2.5 \mathrm{~kg} / \mathrm{d} ; 95 \%$ CI: $1.6,3.4 ; P<0.001$ ), and having a retained placenta resulted in a decrease in feed intake $(\beta=-1.8 \mathrm{~kg} / \mathrm{d}$; 95\% CI: $-3.0,-0.59 ; P=0.003)$. Feed intake increased over time following calving $(\beta=0.16 \mathrm{~kg} / \mathrm{d} ; 95 \%$ CI: $0.13,0.20 ; P<0.001)$.

\section{DISCUSSION}

The management of pain following calving requires attention, especially with assisted calving where there is increased trauma and tissue damage. In some cases, ap- 
propriate analgesics may be beneficial. Unfortunately, the results from the current study indicate that administration of flunixin meglumine is not recommended.

The increased risk of stillbirth when flunixin meglumine was administered before calving and the increased risk of RP when flunixin meglumine was administered immediately after calving are serious consequences for the animals. No other study has reported the use of this NSAID to address pain after natural calving, but Waelchli et al. (1999) used flunixin following caesarian section and noted an increased risk of retained placenta. The increased risks of stillbirth and retained placenta are presumably related to the antiprostaglandin effects that may be specific to this NSAID; other studies on different NSAIDs, notably meloxicam and ketoprofen, have not shown an increased risk of RP (Richards et al., 2009; Newby et al., 2014).

Nonsteroidal anti-inflammatory drugs may act on different prostaglandin pathways. Cyclooxygenase (COX)-1 activity is mainly responsible for the dayto-day physiological functions, whereas COX-2 activity is generally induced under specific conditions such as inflammation (Vane and Botting, 1996). Inhibition of COX-2 is thought to account for most, and perhaps all, of the therapeutic effects of NSAIDs, whereas the inhibition of COX-1 likely accounts for most of the undesirable side effects such as gastrointestinal irritation, renal toxicity, and inhibition of blood clotting (Lees et al., 2004). Flunixin meglumine is both a COX-1 and a COX-2 inhibitor, but is more selective for COX-1 (Beretta et al., 2005); it has an elimination half-life of 3 to $8 \mathrm{~h}$. Ketoprofen is also a COX-1 and COX-2 inhibitor (predominantly a COX-1 inhibitor; Cryer and Feldman, 1998) but has a very short (2 h) elimination half-life. Thus, the side effects may not be seen with ketoprofen because of the short amount of time that ketoprofen stays in the system compared with flunixin meglumine. Meloxicam is known to be a preferential
COX-2 inhibitor (Beretta et al., 2005), thus targeting inflammatory processes rather than physiological functions, which could explain, in part, the differences seen with respect to the lack of effect on the risk of RP following meloxicam administration.

The administration of flunixin immediately after calving resulted in an increase in rectal temperature within $2 \mathrm{~d}$ following parturition. Cows administered flunixin meglumine following parturition and daily for the first 3 DIM had an increased risk of high temperature over the first 7 DIM (Shwartz et al., 2009). Shwartz et al. (2009) also observed a decrease in DMI in the flunixin meglumine group, but found no effects of treatment on milk yield in the 26 multiparous animals from their study. In contrast, in the present study, we detected no effect of flunixin meglumine on the DMI recorded, although this was recorded only at the EDRC site. However, we did observe reduced milk production (during the first 14 DIM) in animals that received flunixin meglumine compared with the placebo group.

Not surprisingly, we found that multiparous cows ate more and produced more compared with primiparous animals. Assistance at calving resulted in lower milk production and increased odds of both RP and other disease outcomes. Furthermore, having RP decreased DMI and milk production and increased the odds of metritis. Dystocia, often resulting in assistance at calving (easy pull by one person, hard pull by more than one person and (or) with mechanical assistance, or caesarian section), is known to reduce productivity for farms and to affect welfare of the dam and sometimes the calf (Lombard et al., 2007; Mee et al., 2008; Atashi et al., 2012). Further research is now needed to find better ways of managing the pain following calving, especially after assisted calving, including the assessment of more appropriate analgesics.

We conclude that flunixin meglumine increases the risk of stillbirth and retained placenta. Our results sup-

Table 2. The effects of high rectal temperature and disease outcomes on combined milk weights for primiparous animals [total $\mathrm{n}=430$; placebo $(\mathrm{P}): \mathrm{n}=213$; flunixin meglumine $(\mathrm{B}): \mathrm{n}=217$ ] and for cows (total $\mathrm{n}=891 ; \mathrm{P}: \mathrm{n}=448 ; \mathrm{B}: \mathrm{n}=443$ ) from the Green Meadow Farms (GMF) and the Elora Dairy Research Centre (EDRC) trial sites

\begin{tabular}{|c|c|c|c|c|c|}
\hline Outcome & Prevalence & Model variable & Odds ratio & $95 \% \mathrm{CI}$ & $P$-value \\
\hline \multirow{2}{*}{ Retained placenta (RP) } & $\mathrm{P}=40 ; \mathrm{B}=91$ & Treatment (B) & $\begin{array}{l}1.0 \\
2.6\end{array}$ & $\begin{array}{l}1.2,2.2 \\
1.7,3.8\end{array}$ & $<0.001$ \\
\hline & & Assisted calving & 2.0 & $1.4,3.0$ & $<0.001$ \\
\hline \multirow[t]{2}{*}{ Metritis } & $\mathrm{P}=175 ; \mathrm{B}=223$ & Treatment (B) & 1.2 & $0.90,1.6$ & 0.24 \\
\hline & & $\mathrm{RP}^{2}$ & 19.1 & $11.7,31.1$ & $<0.001$ \\
\hline
\end{tabular}

\footnotetext{
${ }^{1}$ High temperature $=$ rectal temperature $\geq 39.4^{\circ} \mathrm{C}$.

${ }^{2}$ Note: $\mathrm{RP}$ was a confounder in the metritis model and removing $\mathrm{RP}$ variable leads to treatment odds ratio $=1.5,95 \% \mathrm{CI}: 1.1,1.9, P=0.003$, meaning that metritis is driven by RP.
} 
port the current caution on the use of Banamine for use in cattle around parturition (Merck Animal Health, 2013).

\section{ACKNOWLEDGMENTS}

We thank the staff at Green Meadow Farms (Elsie, MI) and the Elora Dairy Research Centre (University of Guelph, Elora, ON, Canada) for their help, and OMAFRA (Elora, ON, Canada) and Merck Animal Health (Madison, NJ) for funding.

\section{REFERENCES}

Atashi, H., A. R. Abdolmohammadi, A. Asaadi, A. Akhlaghi, M. Dadpasand, and Y. Jafari Ahangari. 2012. Using an incomplete gamma function to quantify the effect of dystocia on the lactation performance of Holsten dairy cows in Iran. J. Dairy Sci. 95:2718 2722.

Beretta, C., G. Garavaglia, and M. Cavalli. 2005. COX-1 and COX-2 inhibition in horse blood by phenylbutazone, flunixin, carprofen and meloxicam: An in vitro analysis. Pharmacol. Res. 52:302-306.

Bionaz, M., E. Trevisi, L. Calamari, F. Librandi, A. Ferrari, and G. Bertoni. 2007. Plasma paraoxonase, health, inflammatory conditions, and liver function in transition dairy cows. J. Dairy Sci. 90:1740-1750.

Cryer, B., and M. Feldman. 1998. Cyclooxygenase-1 and cyclooxygenase-2 selectivity of widely used nonsteroidal anti-inflammatory drugs. Am. J. Med. 104:413-421.

Kelton, D. F., K. D. Lissemore, and R. E. Marting. 1998. Recommendations for recording and calculating the incidence of selected clinical diseases of dairy cattle. J. Dairy Sci. 81:2502-2509.
Lees, P., M. F. Landoni, J. Giraudel, and P. L. Toutain. 2004. Pharmacodynamics and pharmacokinetics of nonsteroidal anti-inflammatory drugs in species of veterinary interest. J. Vet. Pharmacol. Ther. 27:479-490.

Lombard, J. E., F. B. Garry, S. M. Tomlinson, and L. P. Garber. 2007. Impacts of dystocia on health and survival of dairy calves. J. Dairy Sci. 90:1751-1760.

Mee, J. F. 2008. Prevalence and risk factors for dystocia in dairy cattle. Vet. J. 176:93-101.

Mee, J. F., D. P. Berry, and A. R. Cromie. 2008. Prevalence of, and risk factors associated with, perinatal calf mortality in pasturebased Holstein-Friesian cows. Animal 2:613-620.

Merck Animal Health. 2013. Banamine ${ }^{\circledR}$. In the Compendium of Veterinary Products. Merck Animal Health, Madison, NJ.

Newby, N. C., D. L. Pearl, S. J. LeBlanc, K. E. Leslie, M. A. G. von Keyserlingk, and T. F. Duffield. 2013. Effects of meloxicam on milk production, behavior, and feed intake in dairy cows following assisted calving. J. Dairy Sci. 96:3682-3688.

Newby, N. C., D. Renaud, R. Tremblay, and T. F. Duffield. 2014. Evaluation of the effects of treating dairy cows with meloxicam at calving on retained fetal membranes risk. Can. Vet. J. 55:11961199.

Richards, B. D., D. H. Black, R. M. Christley, M. D. Royal, R. F. Smith, and H. Dobson. 2009. Effects of the administration of ketoprofen at parturition on the milk yield and fertility of HolsteinFriesian cattle. Vet. Rec. 165:102-106.

Shwartz, G., K. L. Hill, M. J. VanBaale, and L. H. Baumgard. 2009. Effects of flunixin meglumin on pyrexia and bioenergetics variables in postparturient dairy cows. J. Dairy Sci. 92:1963-1970.

Vane, J. R., and R. M. Botting. 1996. Mechanism of action of antiinflammatory drugs. Scand. J. Rheumatol. Suppl. 102:9-21.

Waelchli, R. O., R. Thun, and H. Stocker. 1999. Effect of flunixin meglumine on placental expulsion in dairy cattle after a caesarean. Vet. Rec. 144:702-703. 